\title{
Statistical Aspects of Community Health and Nutrition
}

\section{M. Pandey}

Former Professor and Head, Department of Biostatistics and Health Informatics, Sanjay Gandhi Postgraduate Institute of Medical Sciences, Lucknow, Uttar Pradesh

\begin{tabular}{|c|c|c|c|c|c|c|c|c|}
\hline Abstract & Introduction & Methodology & $\underline{\text { Results }}$ & Conclusion & References & Citation & \multicolumn{2}{|c|}{ Tables / Figures } \\
\hline \multicolumn{9}{|c|}{ Corresponding Author } \\
\hline \multicolumn{8}{|c|}{$\begin{array}{l}\text { Prof. C.M.Pandey, Former Professor and Head, Department of Biostatistics and Health Informatics, Sanjay } \\
\text { Gandhi Postgraduate Institute of Medical Sciences, Lucknow, Uttar Pradesh } \\
\text { E Mail ID: cmpandey@sgpgi.ac.in }\end{array}$} & 口is \\
\hline
\end{tabular}

\section{Citation}

Pandey CM. Statistical Aspects of Community Health and Nutrition. Indian J Comm Health. 2020;32(2):468.

Source of Funding: Nil Conflict of Interest: None declared

\section{Article Cycle}

\begin{tabular}{|c|}
\hline Received: 05/06/2020; Revision: 14/06/2020; Accepted: 21/06/2020; Published: 30/06/2020 \\
\hline This work is licensed under a Creative Commons Attribution 4.0 International License. \\
\hline
\end{tabular}

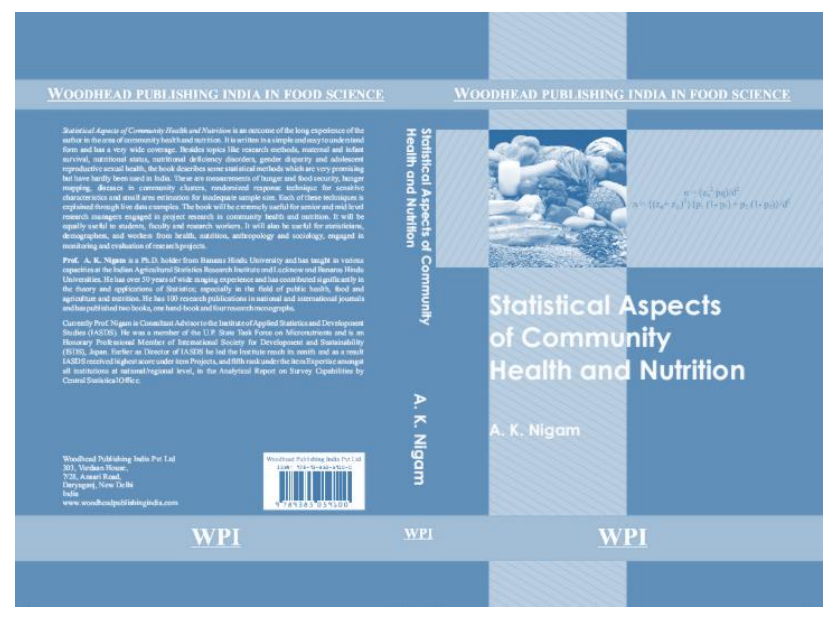

One of the most common problems with the area of health and nutritional research is the limited number of quality books available that can provide research methodology, health indicators and their trend in a single volume. Statistical Aspects of Community Health and Nutrition is a one of the problem-based text book which completely fulfils the gap and stands to our expectations.

This book is a single but comprehensive resource on maternal and infant mortality, anemia especially in adolescents and women in reproductive age group and, their causes, prevention, evaluation and validation methods including 30 clusters design, logistic regression and findings of recent relevant studies. Despite above, author also discusses the food insecurity and hunger, tuberculosis, influenza like prevalent diseases, their hotspot and available estimates, techniques for analyzing multiple response data, and small area estimation.

The author presents statistical concepts in fairly simple language. This is an excellent resource and reference for students, teachers, and health professionals. It is also an excellent book for medical investigators to plan and design medical research including interpretation of available evidence. This is one of the few books that presents hard to understand statistical concepts applied to real-world health data in most simple way. The contents are extremely useful for researchers, program managers and professionals in the area of human nutrition.

It is hoped that all health researchers will find this book useful, especially those who do not have the time or interest in getting comprehensive training in biostatistics, and need to understand these concepts in their professional careers.

* Published by Woodhead Publishing India Pvt Ltd, Ansari Road, Daryaganj, New Delhi 